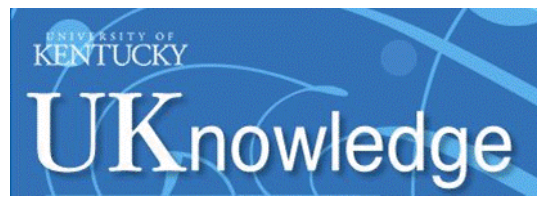

University of Kentucky

UKnowledge

\title{
Inductance Testing According to the New IEEE Std 1812-Application and Possible Extensions for IPM Machines
}

\author{
Vandana Rallabandi \\ University of Kentucky, vandana.rallabandi@uky.edu \\ Narges Taran \\ University of Kentucky, narges.taran@uky.edu \\ Dan M. Ionel \\ University of Kentucky, dan.ionel@uky.edu \\ Ping Zhou \\ ANSYS, Inc.
}

Follow this and additional works at: https://uknowledge.uky.edu/peik_facpub

Part of the Power and Energy Commons

Right click to open a feedback form in a new tab to let us know how this document benefits you.

\section{Repository Citation}

Rallabandi, Vandana; Taran, Narges; Ionel, Dan M.; and Zhou, Ping, "Inductance Testing According to the New IEEE Std 1812-Application and Possible Extensions for IPM Machines" (2017). Power and Energy Institute of Kentucky Faculty Publications. 44.

https://uknowledge.uky.edu/peik_facpub/44

This Conference Proceeding is brought to you for free and open access by the Power and Energy Institute of Kentucky at UKnowledge. It has been accepted for inclusion in Power and Energy Institute of Kentucky Faculty Publications by an authorized administrator of UKnowledge. For more information, please contact UKnowledge@lsv.uky.edu. 


\title{
Inductance Testing According to the New IEEE Std 1812-Application and Possible Extensions for IPM Machines
}

\author{
Digital Object Identifier (DOI) \\ https://doi.org/10.1109/ECCE.2017.8096742
}

\section{Notes/Citation Information}

Published in 2017 IEEE Energy Conversion Congress and Exposition (ECCE).

(C) 2017 IEEE Copyright Notice. "Personal use of this material is permitted. Permission from IEEE must be obtained for all other uses, in any current or future media, including reprinting/republishing this material for advertising or promotional purposes, creating new collective works, for resale or redistribution to servers or lists, or reuse of any copyrighted component of this work in other works."

The document available for download is the authors' manuscript version that is accepted for publication. The final published version is copyrighted by IEEE and available as: V. Rallabandi, N. Taran, D. M. Ionel and P. Zhou, "Inductance testing according to the new IEEE Std 1812-application and possible extensions for IPM machines," Rec. 2017 IEEE Energy Conversion Congress and Exposition (ECCE), Cincinnati, OH, 2017, pp.4302-4308. doi: 10.1109/ECCE.2017.809674 


\section{Inductance Testing According to the New IEEE Std 1812-Application and Possible Extensions for IPM Machines}

\author{
Vandana Rallabandi, Narges Taran, Dan M. Ionel \\ Department of Electrical and Computer Engineering \\ University of Kentucky, Lexington, KY, USA \\ Emails: vandana.rallabandi@uky.edu,narges.taran@uky.edu,dan.ionel@uky.edu
}

\author{
Ping Zhou \\ ANSYS, Inc. \\ Pittsburgh, PA, USA \\ Email: ping.zhou@ansys.com
}

\begin{abstract}
Equivalent circuit parameters are very important for permanent magnet synchronous machines since they serve as the basis for performance estimation and implementation of power electronic drives controls. Specified in the newly approved IEEE Std 1812, a short-circuit test can be employed, in combination with an open-circuit measurement, in order to determine the back emf and the synchronous inductance. In this paper, it is shown that for interior permanent magnet (IPM) machines this approach can be used only to determine the d-axis inductance and additional and separate measurements are required for the q-axis inductance. In this respect, one method widely used in industry, which involves locked-rotor measurements at variable voltage and constant frequency supply, is studied in detail. Other lockedrotor methods based on DC current supply and static torque versus rotor position measurements are introduced for determining qaxis inductance in combination with the standardized opencircuit and short-circuit tests. Test results on an IPM motor design with non-sinusoidal back emf, relatively high torque ripple, and low leakage for the IEEE Std 1812 approach and the newly proposed method for inductance determination are both compared with those from finite element (FE) based simulations.
\end{abstract}

Index Terms-Permanent magnet machine, parameter estimation, inductance, d-axis, q-axis, short-circuit test, IEEE Std 1812.

\section{INTRODUCTION}

Equivalent circuit parameters, serving as the basis for performance estimation and control implementations are of utmost importance for permanent magnet synchronous machines (PMSM). The IEEE Std 1812 discusses the measurement of inductance by performing a short-circuit test [1]. While this allows the determination of $d$-axis inductance, a method to find out the $q$-axis inductance is not included in the standard.

Standstill test of a PMSM, which allows determination of both $\mathrm{d}$ and $\mathrm{q}$ axes inductances is discussed in [2]-[5]. A method commonly used in the industry involves locking the rotor at different positions. Variable voltage at a constant frequency is applied such that the current is constant. The advantage of this method is minimal equipment requirements. Estimation of the $\mathrm{d}$ and $\mathrm{q}$ axes parameters as the result of a DC step response test is discussed in [6]. Tests at standstill conditions neglect slot harmonics and core losses, which can be accounted for in tests under running conditions [5], [7], [8].
In a more recent work, the short-circuit test is used to extract the $d$-axis inductance of an IPM machine. Different values of an external reactance during short-circuit yield the $d$-axis inductance as a function of $d$-axis current. The difference between $\mathrm{d}$ and $\mathrm{q}$ axes inductances is obtained from tests at standstill [9].

For interior permanent magnet (IPM) machines the approach for inductance estimation, described in the newly approved IEEE Std 1812, can be used only to determine the $d$-axis inductance. Separate methods are required to determine the $q$-axis inductance. In this paper, the advantages and limitations of the AC standstill test widely used in the industry are discussed. An alternative locked-rotor method based on DC current supply, which involves static torque versus rotor position measurements is introduced for determining $q$-axis inductance. This method is proposed to be used in conjunction with the standardized open-circuit and short-circuit tests. It requires an in line torque transducer and provides a measurement of the torque capability without a power electronic drive.

Virtual tests, i.e. computationally equivalent models for different tests including short-circuit, open-circuit, AC and DC standstill, and full load are developed and compared among each other, and with results from finite element (FE) based simulations for a special IPM motor (Fig. 1). This machine has non-sinusoidal back emf, with 9 stator slots (Fig. 2), 6 rotor poles (Fig. 3), relatively high torque ripple, and low leakage. Experimental test results for the IEEE Std 1812 approach and AC standstill method are compared with those from the virtual tests.

\section{Open And Short Circuit Tests According to the IEEE STD 1812}

Equivalent circuit parameters required from a PM machine are $L_{d}, L_{q}$, and the PM flux linkage on open-circuit. In order to determine the PM flux linkage on open-circuit, a drive motor is used to bring the PMSM up to the desired test speed, and the open-circuit voltage is measured. The differences between the measured (Fig. 4a) and simulated (Fig. 4b) are attributed to the presence of skewing in the prototype. Following the 


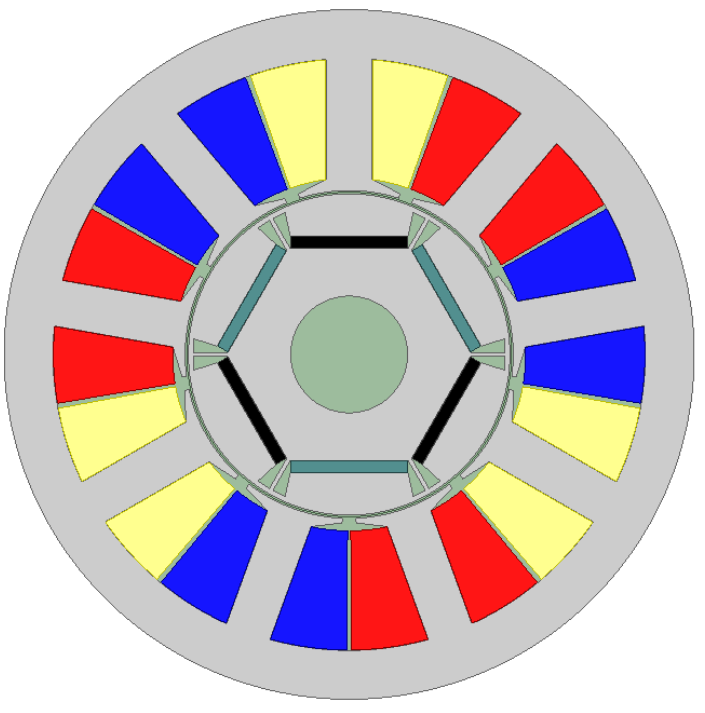

Fig. 1. The cross section of a prototype three-phase IPM motor with concentrated coils, 9 slots and 6 poles, rated for $9 \mathrm{Nm}$ and $3600 \mathrm{rpm}$. The machine was selected on purpose to have a relatively high non-sinusoidal back emf and torque ripple, and substantial axial length in order to minimize the influence of the leakage.

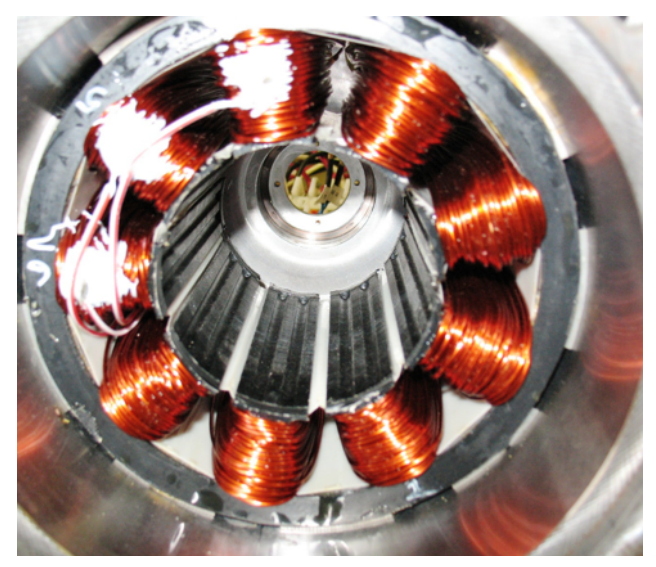

Fig. 2. The stator of the example prototype motor considered in the study.

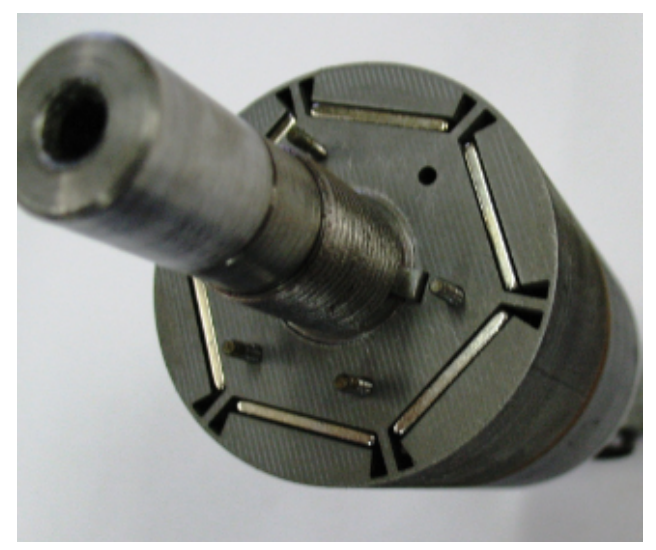

Fig. 3. The rotor of the example prototype motor considered in the study.

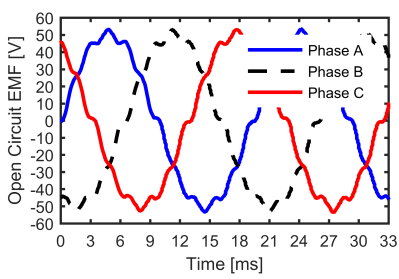

(a) (b)

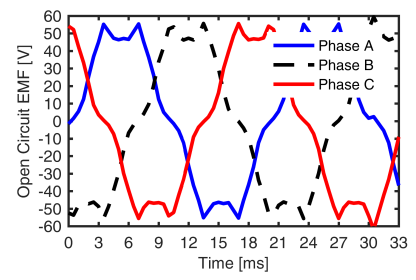

Fig. 4. (a) Measured back emf, and (b) simulated back emf at $1026 \mathrm{rpm}$. The prototype machine is skewed, while skew is not considered in the simulation study.

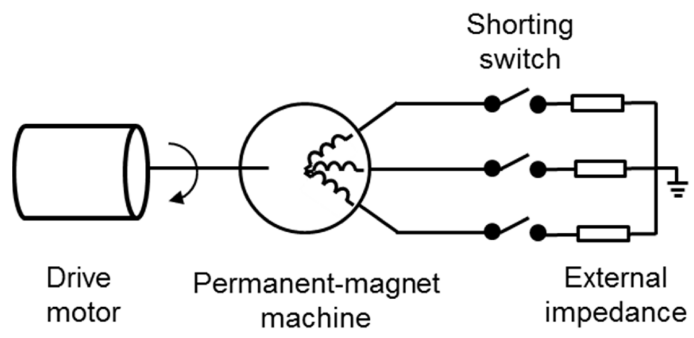

Fig. 5. Short-circuit test configuration based on IEEE Std 1812 [1].

measurement of open-circuit voltage, the machine is shortcircuited by closing the short-circuit contactor (Fig. 5) and the short-circuit current is measured at steady state. The PM flux linkage, $\psi_{m}$, and $d$-axis inductance, $L_{d}$, are obtained using:

$$
\begin{array}{r}
\psi_{m}=\frac{E_{o c}}{\omega}, \quad Z=\frac{V_{o c}}{I_{s c}}, \\
X_{d}=\sqrt{Z^{2}-R^{2}}, \quad L_{d}=\frac{X_{d}}{2 \pi f},
\end{array}
$$

where $E_{o c}$ is the peak value of the open-circuit voltage; $\omega$, the angular frequency; $V_{o c}$, the rms value of the open-circuit voltage; $I_{s c}$, the rms value of the short-circuit current; $X_{d}$, the $d$-axis reactance; $\mathrm{R}$, the phase resistance, and $f$, the electrical frequency. It is observed that as $V_{o c}$ and $X_{d}$ are directly proportional to speed, $I_{s c}$ is independent of speed. The phase resistance can be obtained by monitoring the shortcircuit power, or by the use of a multimeter. A virtual shortcircuit test on an IPM with 9 stator slots and 6 rotor poles is carried out using ANSYS Maxwell ${ }^{\circledR}$ software (Fig. 6, Fig. 7). The lower flux density during short-circuit than on load (Fig. 8, Fig. 9) would lead to an over-estimation of $L_{d}$. The connection of an external impedance in series with the phases would lead to a reduction in the short-circuit current. However, the field distribution obtained even at lower shortcircuit currents is not a correct representation of the full load operating conditions (Fig. 10), since the short-circuit stator flux is always demagnetizing. 


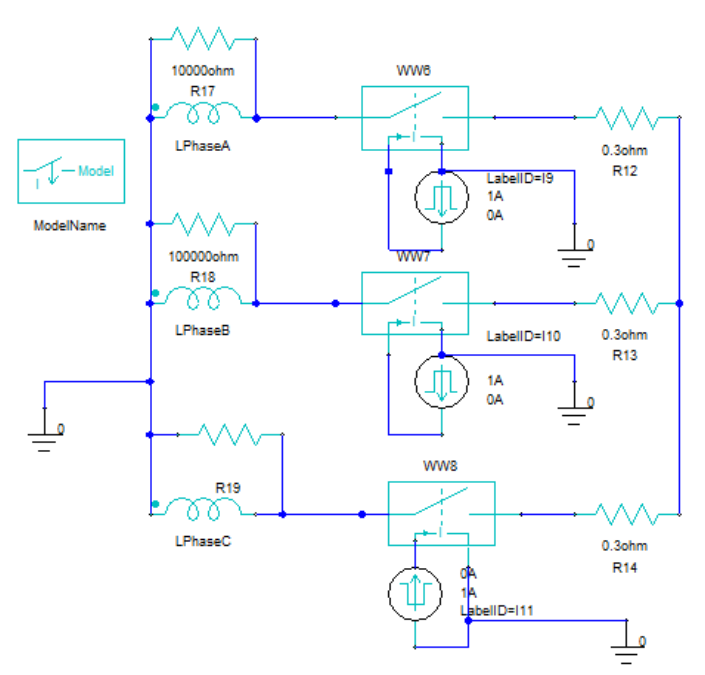

Fig. 6. The external circuit used for a virtual short-circuit test with ANSYS Maxwell ${ }^{\circledR}$ software.

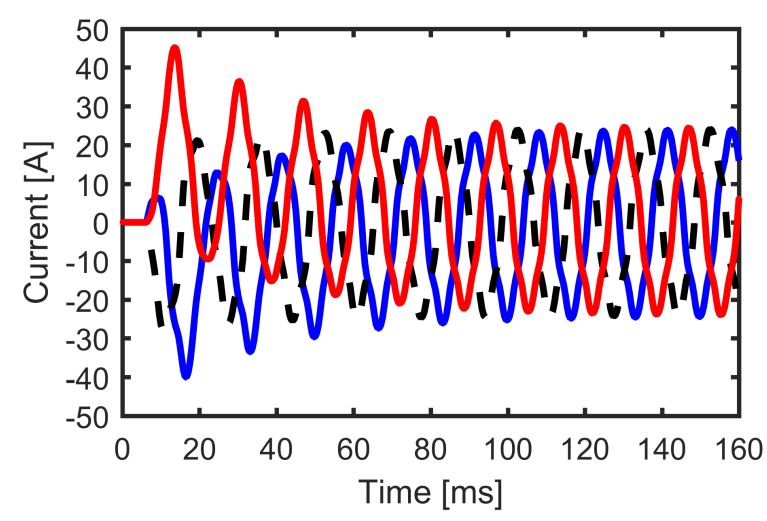

Fig. 7. Three phase currents under a sudden short-circuit applied at $t=16.66$ ms.

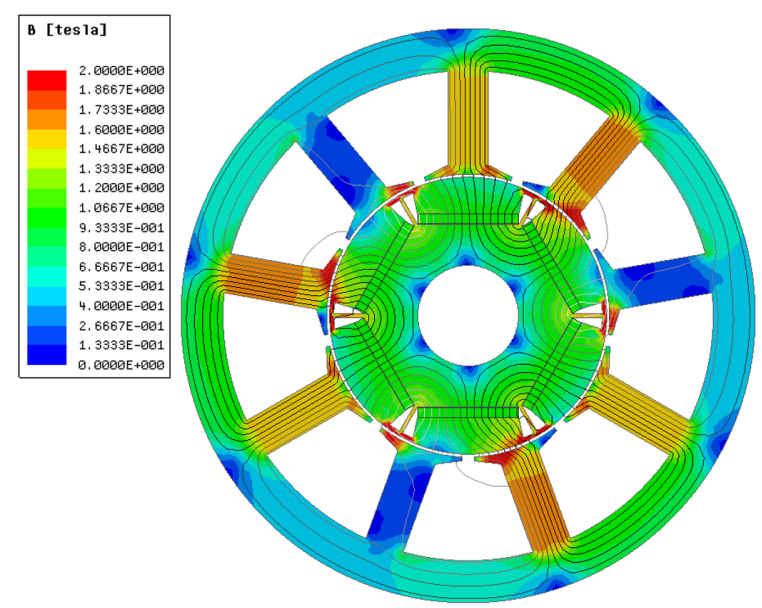

Fig. 8. Flux lines at the full load operating condition. Higher values of the flux density and the PM rotor flux lines substantially closing through the stator core, including back iron are observed.

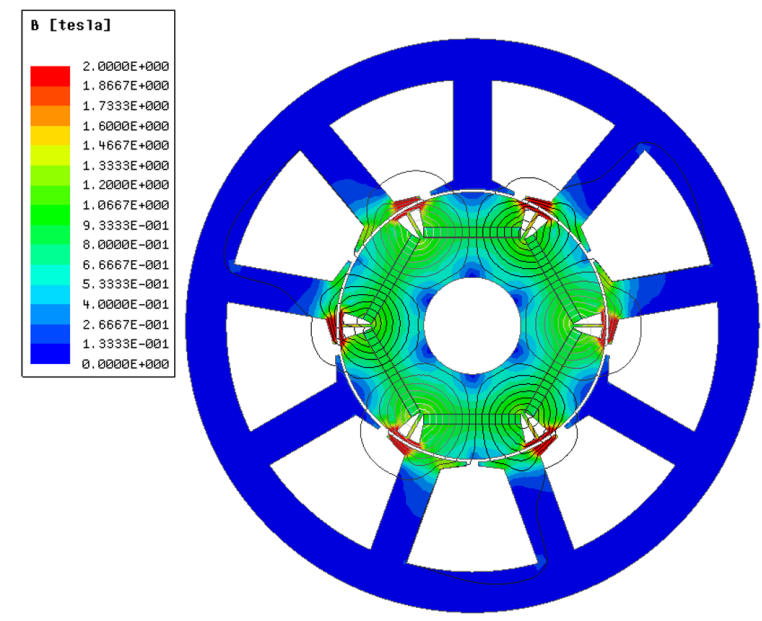

Fig. 9. Flux lines under short-circuit. Very low values of the flux density and the PM rotor flux lines substantially closing through the air-gap and tooth tips of the stator due to the demagnetizing effect of the short cirucit current may be noted.

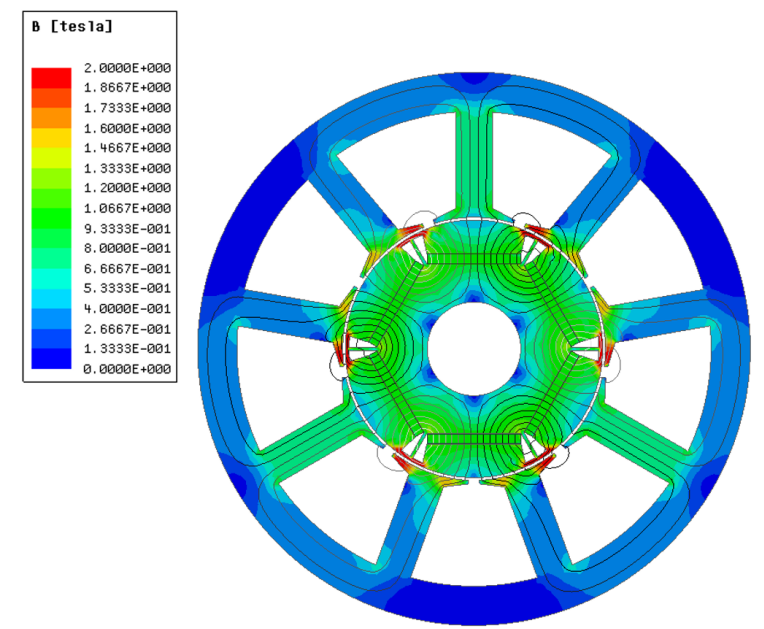

Fig. 10. Flux lines under short-circuit, with an external reactance in series with the phase winding. The flux density is much lower than on full load due to the demagnetizing effect of current.

\section{STATIC TESTS FOR TORQUe AND Q-AXIS INDUCTANCE}

With the use of the short-circuit test to determine the $d$-axis inductance, and open-circuit test to find out the PM flux linkage, a static torque measurement can be used in order to obtain the $q$-axis inductance. The phases may be connected as shown in Fig. 11a or Fig. 11b. DC current is then supplied to the phases. The connection of Fig. 11a with $I_{b}=I_{c}=\frac{-I_{a}}{2}$, results in an MMF parallel to the phase A axis and the rotor rotates to align its $d$-axis with it. On the other hand, if the phases are connected as shown in Fig. 11b, the currents are $I_{b}=-I_{c}$, and $I_{a}=0$ and it results in a $q-$ axis excitation, with the rotor held in the same position. The static torque is measured by locking the rotor in different intermediate positions (Fig. 12). Rotor movement allows different values 
of $I_{d}$ and $I_{q}$, with the same circuit connection of Fig. 11b, i.e. the coils are excited from phase B and phase A is left open. The values of $I_{d}$ and $I_{q}$ are given by:

$$
I_{d}=\frac{2}{3} I_{b}\left[\cos \left(\theta+\frac{2 \pi}{3}\right)-\cos \left(\theta-\frac{2 \pi}{3}\right)\right],
$$

and

$$
I_{q}=\frac{2}{3} I_{b}\left[\sin \left(\theta+\frac{2 \pi}{3}\right)-\sin \left(\theta-\frac{2 \pi}{3}\right)\right],
$$

where $\theta$ is the angular separation between the $q$-axis of the rotor and the axis of phase $\mathrm{A}$, and $I_{b}$ is the current in the circuit. The value of $\lambda_{m}$, is obtained by holding the rotor in the $q$-axis position as:

$$
\lambda_{m}=\frac{2 T_{e m}}{3 p I_{q}}
$$

where $T_{e m}$ is the electromagnetic torque and $p$ is the number of pole pairs. With the value of $L_{d}$ from short circuit, $L_{q}$ may be determined using,

$$
L_{q}=L_{d}+\frac{\lambda_{m}}{I_{d}}-\frac{2 T_{e m}}{3 p I_{d} I_{q}},
$$

In principle, locking the rotor in two intermediate positions, including the $q-$ axis is enough to determine $L_{q}$. The $q$-axis inductance may be obtained at required operating point by locking the rotor in the position resulting in the desired values of $I_{d}$ and $I_{q}$. Errors may be introduced in this method due to cogging torque, which is not included in (5). This may, to some extent, be mitigated by conducting the test at rated conditions.

An alternative method involves holding the rotor stationary and injecting different values of $I_{a}, I_{b}$ and $I_{c}$, which is readily done using an inverter. Since PMSMs are generally provided with drives, this method adds no extra cost [9]. The torque is expressed by:

$$
T_{e m}=A \cos (\gamma)+B \sin (2 \gamma), \quad \gamma=\tan ^{-1} \frac{I_{d}}{I_{q}},
$$

The coefficients $A$ and $B$ are functions of machine parameters, and given by,

$$
\lambda_{m}=\frac{2 A}{3 p I_{s}}, \quad L_{q}-L_{d}=\frac{4 B}{3 p I_{s}^{2}},
$$

where $I_{s}$ is the phase current. Solving (6) for two different values of $\gamma$ and $T_{e m}$ yields the values of $A$ and $B$. The difference $L_{q}-L_{d}$ is then determined from (4) and the value of $L_{d}$ from the short-circuit test is used to obtain $L_{q}$. A limitation of this test is that in (6), $A$ remains substantially constant with $\gamma$, while only $B$ is a function of $\gamma$. However, in the model, both $A$ and $B$ are determined as functions of $\gamma$. This limitation may be mitigated on estimating $A$ by maintaining $\gamma=0 \mathrm{deg}$. The term $B$ is then obtained as a function of $\gamma$ on performing the test at different operating conditions.

In addition to these tests, the inductance can be determined by observing the stator current response to a voltage step, which may be applied by using an inverter [10]. The rotor is locked in the desired positions using, for instance, the circuit

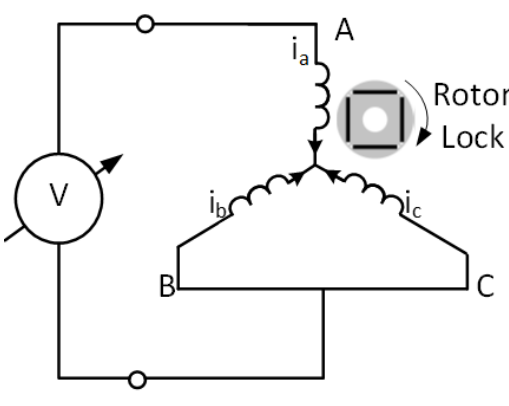

(a)

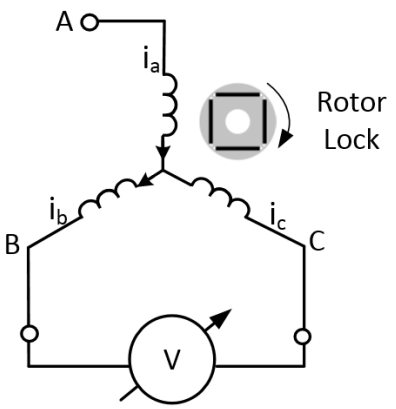

(b)
Fig. 11. Circuit connections for the standstill test with a) Phase A connected in series with the parallel combination of Phases B and C, and voltage applied between phases $\mathrm{A}$ and $\mathrm{B}$. The resultant MMF is oriented along the axis of phase $\mathrm{A}$, and the rotor rotates to align its $d$-axis along it and $\mathrm{b}$ ) voltage applied across phases $\mathrm{B}$ and $\mathrm{C}$, resulting in an MMF perpendicular to the phase A axis. If the rotor is held locked in the previous position, this is a $q$-axis excitation. The DC standstill tests use a variable DC source, while the AC tests use a variable voltage AC supply.

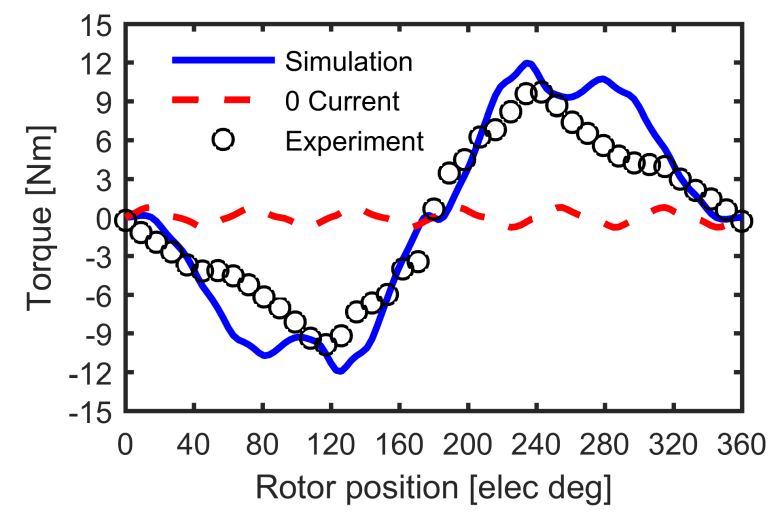

Fig. 12. DC supply standstill torque measured and simulated with a virtual test procedure. Also shown is the cogging torque developed without any current flowing through the stator winding. For experiments an in-line torque transducer is required between the shaft and a mechanical locking device.

connection of Fig. 11a. The current in response to a voltage step is:

$$
I=\frac{V}{R}\left(1-e^{\frac{-R t}{L}}\right),
$$

where $V$ is the applied DC voltage; $I$, the current response; $\mathrm{L}$, the line-line inductance at the corresponding rotor position, and $\mathrm{R}$, the resistance. The value of the phase resistance is determined from the steady state value of the current, and the value of L may then be subsequently determined from (8), knowing the instantaneous values of current. The $d$ and $q$ axes inductances are obtained by multiplying $\mathrm{L}$ at these positions by $\frac{2}{3}$.

\section{InduCtance FROM THE AC STANDSTILl TeST}

In this method, the rotor is locked at different positions and voltages are applied to force a given amount of current through the coils. For the circuit connections of Fig. 11a, the relation between the phase currents is $I_{b}=I_{c}=-\frac{I_{a}}{2}$. The inductance 


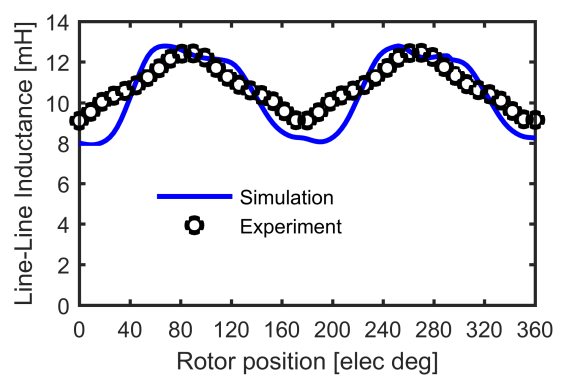

(a)

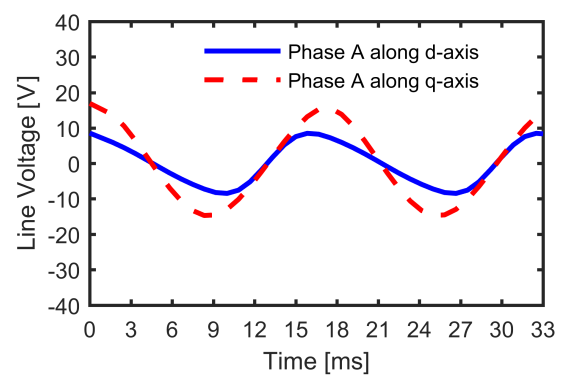

(b)

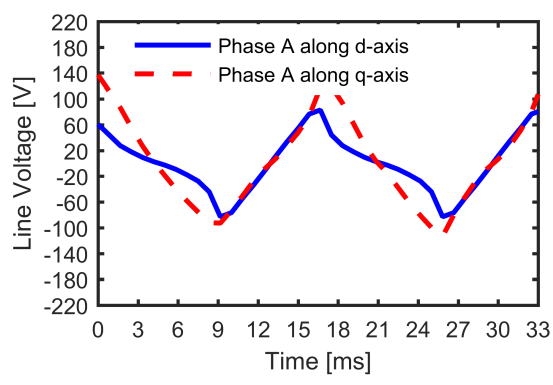

(c)

Fig. 13. Line-line inductance at 15A, obtained from the standstill test using connection of (Fig. 11a). In the measurement, the applied voltage is substantially constant to force an average RMS current of 15A, while in simulation, the current is held constant (a). Voltages induced in the windings in the standstill AC test for a line current of $2 \mathrm{~A}$ (b) and for a line current of $15 \mathrm{~A}$ (c). The waveform is non sinusoidal, particularly at high currents leading to errors in calculation. In the voltage driven experiment, the currents would be non-sinusoidal leading to errors.

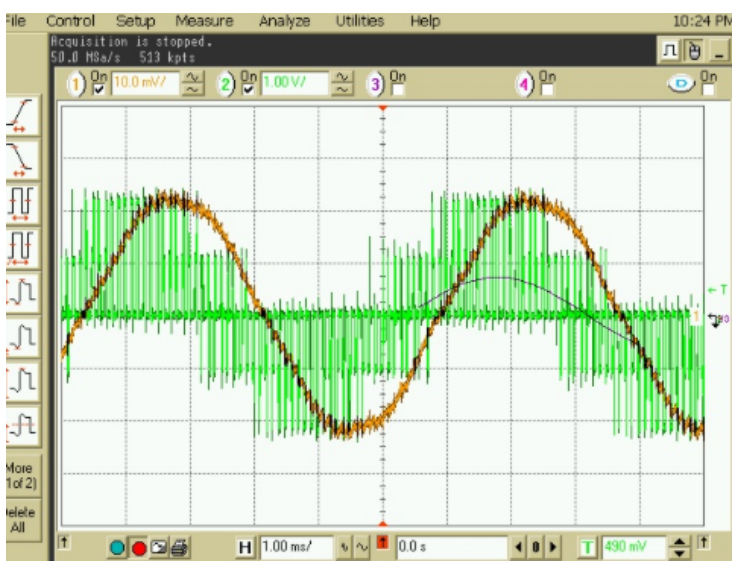

Fig. 14. Example of measured PWM voltage and electronically regulated current.

with the rotor locked at different positions is then obtained from:

$$
Z=\frac{V}{I}, \quad R=\frac{P}{I^{2}}, \quad L=\frac{\sqrt{Z^{2}-R^{2}}}{2 \times \pi f},
$$

where $V$ is the rms voltage at different positions; $I$, the rms current; $Z$, the total impedance; $P$, the power absorbed; $R$, an equivalent resistance that includes the winding and core loss resistance; and $L$, the line inductance. To obtain the $\mathrm{d}$ and $\mathrm{q}$ axes inductances, the line inductance at these positions is multiplied by $\frac{2}{3}$. The windings may also be connected as shown in Fig. 11b. In this case, the relation between the phase currents is: $I_{a}=-I_{b}, I_{c}=0$. Locking the rotor in different positions, the line inductance seen by the supply changes. The line inductance is obtained from (3). It is possible to prove that $L_{d}$ and $L_{q}$ can be calculated using:

$L_{q}=\frac{L_{0}+L_{90}}{4}+\frac{L_{0}-L_{90}}{2}, L_{d}=\frac{L_{0}+L_{90}}{4}-\frac{L_{0}-L_{90}}{2}$,

where $L_{0}$ is the line inductance when the rotor $q$-axis is aligned with the magnetic axis of phase A, and $L_{90}$ is the line inductance when the rotor $d$-axis is aligned with the magnetic axis of phase A. The inductances obtained by estimation from measurement are compared with those obtained from a virtual standstill test set up in ANSYS Maxwell ${ }^{\circledR}$ software (Fig. 13a). In contrast with the experiment wherein voltage is kept substantially constant, the simulation is current driven. This difference is because of the difficulty in modeling voltage driven FEA problems, which require large simulation times to attain steady state.

A major drawback of the AC standstill test is that the magnetic field established within the electric machine is different from the rotating one, which is specific to the running operation. Another challenge may be represented by the torque ripple and strong vibrations, especially at very high current loading, which may cause variations in the measurements.

\section{OTHER TESTS AND Discussion}

In addition to the real and virtual experiments described in the previous sections, the on-load performance of the motor under study has been measured at rated speed using a vector controlled power electronic drive and corresponding FE simulations have been conducted. Special set-ups included those for operation at the maximum torque per ampere (MTPA) condition and on-load with zero $d$-axis current (ID0). In such cases, using the value of $L_{d}$ derived from the short circuit test, the $q$-axis inductance and the PM flux linkage can be calculated as:

$$
L_{q}=\frac{V_{a} \sin \varphi}{2 \pi f I_{a}}, \quad \lambda_{m}=\frac{2 T_{e m}}{3 p I_{q}},
$$

where $V_{a}$ and $I_{a}$ are the rms values of the fundamental harmonic of phase voltage and current, respectively, and $\varphi$ is the power factor angle.

Experiments and data post-processing require special care. For example, the electromagnetic torque, $T_{e m}$, is obtained by adding to the measured shaft torque, a component corresponding to all the motor power losses except the stator winding losses. Under current regulated control, the PWM voltage supply waveform is highly distorted and has a rich high frequency harmonic content as illustrated in Fig. 14. Therefore, caution must be exerted in applying filtering techniques and measuring 
TABLE I

DQ MOTOR PARAMETERS, INDUCTANCES AND PM FLUX LINKAGE DETERMINED THROUGH REAL AND VIRTUAL TESTS AND FE SIMULATIONS. FOR ANY OF THE TESTS LISTED, AT LEAST ONE PARAMETER CANNOT BE DIRECTLY DETERMINED AS DENOTED BY N/A.

\begin{tabular}{|c|c|c|c|c|c|c|c|c|}
\hline & $\begin{array}{c}\text { AC Standstill } \\
\text { Rated } \\
\text { Virtual }\end{array}$ & $\begin{array}{l}\text { AC Standstill } \\
\text { Rated } \\
\text { Experimental }\end{array}$ & $\begin{array}{l}\text { Open/Short- } \\
\text { Circuit } \\
\text { Virtual }\end{array}$ & $\begin{array}{l}\text { Load MTPA } \\
\text { FE Simulation }\end{array}$ & $\begin{array}{c}\text { Load ID0 } \\
\left(I_{q}=21 A\right) \\
\text { Virtual }\end{array}$ & $\begin{array}{c}\text { Load ID0 } \\
\left(I_{q}=21 A\right) \\
\text { Experimental }\end{array}$ & $\begin{array}{c}\text { DC step } \\
\text { Rated } q-\text { axis } \\
\text { Virtual }\end{array}$ & $\begin{array}{c}\text { DC step } \\
\text { Rated } d-\text { axis } \\
\text { Virtual }\end{array}$ \\
\hline$L_{d} \quad[\mathrm{mH}]$ & 5.3 & 6.1 & 7.2 & 6.7 & N/A & N/A & N/A & 7.3 \\
\hline$L_{q} \quad[\mathrm{mH}]$ & 8.2 & 8.3 & N/A & 7.6 & 7.2 & 9.5 & 7.4 & N/A \\
\hline$\lambda_{m} \quad[\mathrm{~Wb}]$ & N/A & N/A & 0.17 & 0.17 & 0.14 & 0.16 & N/A & N/A \\
\hline
\end{tabular}

TABLE II

INDUCTANCES DETERMINED THROUGH FE SIMULATIONS AT SPECIFIED VALUES FOR THE DQ CURRENT COMPONENTS AND FROM CORRESPONDING DC STANDSTILL VIRTUAL TESTS, WHICH EMPLOY FOR CALCULATIONS THE $d$-AXIS INDUCTANCE ESTABLISHED THROUGH A SHORT CIRCUIT EXPERIMENT.

\begin{tabular}{|c|c|c|c|c|}
\hline & $\begin{array}{r}\text { DC Standstill } \\
\text { Vir. }\end{array}$ & $\begin{array}{r}\text { FE } \\
\text { Sim. }\end{array}$ & $\begin{array}{r}\text { DC Standstill } \\
\text { Vir. }\end{array}$ & $\begin{array}{r}\text { FE } \\
\text { Sim. }\end{array}$ \\
\hline$I_{d}[\mathrm{~A}]$ & -7.2 & -7.2 & -19.9 & -19.9 \\
\hline$I_{q} \quad[\mathrm{~A}]$ & 19.9 & 19.9 & 7.2 & 7.2 \\
\hline$L_{d} \quad[\mathrm{mH}]$ & N/A & 8.0 & N/A & 7.2 \\
\hline$L_{q}[\mathrm{mH}]$ & 10.9 & 7.9 & 8.6 & 9.0 \\
\hline
\end{tabular}

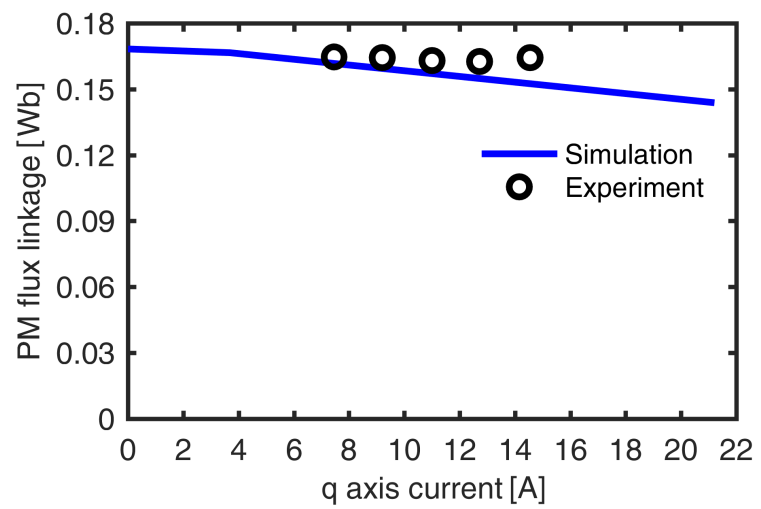

Fig. 15. The variation of the PM flux linkage, $\lambda_{m}$, with the $q$-axis current component, $I_{q}$, derived through FE simulations for a motor model that considers the effect of self and cross-coupling saturation. The reported on-load experimental results were obtained using a power electronic drive, which incorporates a control compensation for saturation. The PM flux linkage calculated based on the experimental open-circuit test data for the back emf is $0.16 \mathrm{~Wb}$.

only the rms values and the power factor corresponding to the fundamental harmonic, in compliance with the principles of the d-q theory.

Based on the FE simulations, which are considering on-load operation with specified values for the dq current components, the inductances are estimated as:

$$
L_{d}=\frac{\lambda_{d}-\lambda_{m}}{I_{d}}, \quad L_{q}=\frac{\lambda_{q}}{I_{q}},
$$

where the PM flux linkage is calculated from an open circuit simulation:

$$
\lambda_{m}=\lambda_{d}, \text { with } I_{q}, I_{d}=0
$$

Parameter values derived based on on-load measurements and FE simulations are listed in Table I together with figures calculated from open and short circuit, AC standstill, DC step real and virtual tests. Additional data from DC standstill procedures is included in Table II.

Before drawing any comparisons, it should be acknowledged that magnetic saturation in IPM motors affects the values of dq parameters, which are, in principle, non-linear functions of the dq current components. Not only that there is a self-axis saturation that will cause the $\mathrm{d}$ and the $q$-axis inductances to be a function of the $\mathrm{d}$ and $q$-axis current, respectively, but there is also a cross-coupling saturation, that will cause for example the $d$-axis inductance and the on-load PM flux linkage to be a function of the $q$-axis current, as explained for example in [11].

Yet, in the current version of the IEEE Std 1812, the emphasis is placed on single parameter values for the $d$-axis parameters, which are calculated based on open-circuit and short-circuit tests. While this may be a simple and pragmatic approach, in order to enable the practical focus to be on the derivation of the likely most important non-linearity of the $q$-axis inductance with the the $q$-axis current, for example through experiments and simulations at the same torque angle and different current, it is maybe open to criticism in terms of capturing the non-linearity of the $d$-axis parameters with respect to the $\mathrm{d}$ and $q$-axis currents, respectively, which is illustrated in Fig. 15. When adding such considerations the challenges previously mentioned for the various testing procedures, the spread of parameter values from Tables I and II should come as no surprise.

A special note is due for the standstill experiments, as these have a distinct advantages in terms of simplified requirements, which do not include the use of a drive. The motor magnetic field pattern in the AC standstill test is largely different to the rotating electromagnetic field during on-load vector controlled operation.

During a DC standstill test the fixed distribution of the stator currents and locked rotor position correspond to one "snap-shot" of the running on-load operation and rotating magnetic field pattern. A major challenge in this case, apart from the relatively large ripple torque and possibly cogging torque pulsations, is represented by the fact that the PM flux linkage and $q$-axis inductance are calculated based on torque measurements, which have to be precise, and $d$-axis inductance is calculated from short-circuit test data. The 
expectations therefore may be that best correlations for the $q$-axis inductance values would be obtained for operation with relatively large values of $d$-axis current similar to the short-circuit current, as exemplified in Table II, which may not be necessarily representative of the typical on-load operating conditions.

\section{CONCLUSION}

The equivalent circuit parameters for the PM synchronous machines are required for the development of control algorithms, application of power electronic drives, and performance estimation. The current IEEE Std 1812 Testing Guide, which has been approved in 2015, fills in a much needed gap in industry by formalizing procedures, including one for an open-circuit and another one for a short-circuit test, which may be employed in order to derive single values for the PM flux linkage and $d$-axis inductance. More work is required though in terms of expanding the scope with standard procedures for determining the $q$-axis inductance and, possibly, quantifying the non-linear saturation effects on all the parameters, both matters being of great interest especially for IPM machines.

In this respect, this paper makes a critical review of methods popular in industry, including AC and DC standstill locked rotor tests and on-load tests with vector controlled drives. An experimental and a two-dimensional FE computational study is conducted on an example IPM motor with relatively high torque ripple and low end effects. A spread of the parameter values resulting from different testing methods is noted and the main relative merits and demerits of each procedure are discussed, supporting a conclusion that more studies, technical information sharing, and professional discussions should take place before reaching recommendations suitable for wide industry acceptance and possible formal standardization.

\section{ACKNOWLEDGMENT}

The support of University of Kentucky, the L. Stanley Pigman endowment and the SPARK program, and of ANSYS Inc. is gratefully acknowledged.

\section{REFERENCES}

[1] "IEEE trial-use guide for testing permanent magnet machines," IEEE Std 1812-2014, pp. 1-56, Feb 2015.

[2] W. Soong, "Inductance measurements for synchronous machines," in Power Engineering Briefing Note Series 2, Oct 2008.

[3] M. Musak and M. S. Tulrajter, "Novel methods for parameters investigation of pm synchronous motors." Acta Technica Corvininesis-Bulletin of Engineering, vol. 6, no. 1, 2013.

[4] J. Kang, "General purpose permanent magnet motor drive without speed and position sensor," Yaskawa Electric America, 2009.

[5] H. B. Ertan and I. Sahin, "Evaluation of inductance measurement methods for pm machines," in Electrical Machines (ICEM), 2012 XXth International Conference on, Sept 2012, pp. 1672-1678.

[6] S. Weisgerber, A. Proca, and A. Keyhani, "Estimation of permanent magnet motor parameters," in Industry Applications Conference, 1997. Thirty-Second IAS Annual Meeting, IAS '97., Conference Record of the 1997 IEEE, vol. 1, Oct 1997, pp. 29-34 vol.1.

[7] M. Kazerooni and N. C. Kar, "Methods for determining the parameters and characteristics of pmsm," in 2011 IEEE International Electric Machines Drives Conference (IEMDC), May 2011, pp. 955-960.

[8] K. M. Rahman and S. Hiti, "Identification of machine parameters of a synchronous motor," IEEE Transactions on Industry Applications, vol. 41 no. 2 , pp. 557-565, March 2005 .

[9] S. A. Odhano, R. Bojoi, E. Armando, G. Homrich, A. F. F. Filho, M. Popescu, and D. G. Dorrell, "Parameter extraction for three phase ipm machines through simple torque tests," in 2015 IEEE Energy Conversion Congress and Exposition (ECCE), Sept 2015, pp. 18921898.

[10] S. Weisgerber, A. Proca, and A. Keyhani, "Estimation of permanent magnet motor parameters," in Industry Applications Conference, 1997. Thirty-Second IAS Annual Meeting, IAS '97., Conference Record of the 1997 IEEE, vol. 1, Oct 1997, pp. 29-34 vol.1.

[11] D. M. Ionel, M. J. Balchin, J. F. Eastham, and E. Demeter, "Finite element analysis of brushless dc motors for flux weakening operation," IEEE Transactions on Magnetics, vol. 32, no. 5, pp. 5040-5042, Sep 1996. 